\title{
The Path to Salvation
}

\author{
Nandini Chatterjee
}

Bengal Physician Journal (2021): 10.5005/jp-journals-10070-7068

\section{INTRODUCTION}

The coronavirus disease-2019 (COVID-19) vaccination drive commenced on January 16, 2021, and within 10 months, the figures for total doses given have reached 113 crores till date with the phenomenal efforts of the scientists, vaccine manufacturers, policymakers, health bodies, and health personnel altogether. However, as the virus continues to mutate and change strategies of attack and wave after wave of the pandemic continues to plague humanity, a number of queries need to be answered.

\section{How Much are we Protected by Different VACCINES?}

No vaccine is $100 \%$ efficacious. Studies revealed that Covaxin has an efficacy of $76-78 \%$ beginning 22 days after the first dose, which increases to $81.3 \%$ after the second dose when it is taken up to 12 weeks later. Efficacy of Covishield vaccine is around $79 \%$ effective overall at preventing symptomatic COVID-19 and 93.4\% effective against severe symptomatic cases but only $63.6 \%$ effective against asymptomatic disease.

Covishield, Covaxin both have also proved to be effective against the new mutant variants with patients showing milder illnesses postvaccination. CDC reported that vaccine effectiveness fell to $66 \%$ in cases of delta variants; however, in comparison with fully vaccinated people, unvaccinated people were 5 times more likely to be infected, 10 times more likely to be hospitalized, and 11 times more likely to die. So it is to be percolated among the populace that it is always preferable to be vaccinated. ${ }^{1,2}$

\section{Is the Booster Dose Needed? What is an Additional Dose?}

The World Health Organization condemned the widespread use of booster doses as it feels, it is redundant to give a third shot to healthy people when in some poor countries the population has not even received one shot. For healthy people, there is no reliable data on the benefits of booster vaccination. However, the CDC has put forward clear indications for booster doses after 6 months of completing vaccine schedule in the following:

- All adults aged 65 years or over

- Frontline health and social care workers

- All those aged above 18 years with underlying health conditions that put them at higher risk of severe COVID-19. People living in care homes

Additional doses may be given to immunosuppressed individuals after 28 days of the last dose.
IPGMER and SSKM Hospital, Kolkata, West Bengal, India

Corresponding Author: Nandini Chatterjee, IPGMER and SSKM Hospital, Kolkata, West Bengal, India, Phone: +91 8145005804 , e-mail: nandinibpj21@gmail.com

How to cite this article: Chatterjee N. The Path to Salvation. Bengal Physician Journal 2021;8(3):61-62.

Source of support: Nil

Conflict of interest: None

\section{What about Vaccination of Children?}

In August 2021, Drug Controller Government of India (DCGI) had granted emergency approval to the ZyCoV-D COVID-19 vaccine for use in adolescents 12 years old and above. ZyCoV-D was developed on a DNA platform using a nonreplicating and nonintegrating plasmid carrying the novel coronavirus gene. In addition, ZyCoV-D is a three-dose intradermal vaccine, which is applied using the needle-free system that can significantly reduce any side effects.

Also, Covaxin COVID-19 vaccine had been awarded by India's Subject Expert Committee Emergency Use Approval to vaccinate children between 2 and $18 .^{3}$

\section{What is the Status of Breakthrough INFECTIONS?}

Although any fully vaccinated person can experience a breakthrough infection, people with weakened immune systems caused by certain medical conditions or treatments (including organ transplants, HIV, and some cancers and chemotherapy) are more likely to have breakthrough infections. ${ }^{4}$

Breakthrough coronavirus infections can cause mild or moderate illness, but the chances of serious COVID-19 are very low, especially for people without comorbidities.

\section{What is Known about Postexposure Prophylaxis?}

The U.S. FDA has issued an EUA for postexposure prophylaxis on close contact exposure in patients at high risk of progression to severe disease and hospitalization with monoclonal antibody cocktails like casirivimab/imdevimab. It may also be given in mild-to-moderate COVID patients with comorbidities within 10 days.

\footnotetext{
(c) The Author(s). 2021 Open Access This article is distributed under the terms of the Creative Commons Attribution 4.0 International License (https://creativecommons. org/licenses/by-nc/4.0/), which permits unrestricted use, distribution, and non-commercial reproduction in any medium, provided you give appropriate credit to the original author(s) and the source, provide a link to the Creative Commons license, and indicate if changes were made. The Creative Commons Public Domain Dedication waiver (http://creativecommons.org/publicdomain/zero/1.0/) applies to the data made available in this article, unless otherwise stated.
} 
It is not to be used in already hospitalized patients who are requiring oxygen therapy or mechanical ventilation.

To conclude, it was estimated that enough vaccine to vaccinate the whole world can be manufactured by January 2022. However, some impediments, like vaccine hoarding, booster shots, and a lack of funding for vaccination infrastructure, may lead to many countries having inadequate vaccination. ${ }^{5}$

While vaccines substantially reduce the probability of infection, breakthrough infections indicate that vaccinated people should continue using preventive measures (wear face masks, social distance, wash hands) to avoid infecting others, especially vulnerable people, particularly in areas with high community spread. So the road to salvation lies in the behavioral choices we embrace in our daily lives while encompassing universal vaccination.

\section{References}

1. Petter E, Mor O, Zuckerman N, et al. Initial real world evidence for lower viral load of individuals who have been vaccinated by BNT162b2. medRxiv 2021. DOI: 10.1101/2021.02.08.21251329.

2. Yeh TY, Contreras GP. Full vaccination suppresses SARS-CoV-2 delta variant mutation frequency. medRxiv 2021. DOI: 10.1101/ 2021.08.08.21261768. S2CID 236965312.

3. Kumar J, Meena J, Kasi SG, et al. COVID-19 vaccine in children: where do we stand? J Indian Pediatr 2021;58(2):194-195. DOI: 10.1007/ s13312-021-2150-5.

4. Rogliani P, Chetta A, Cazzola M, et al. SARS-CoV-2 neutralizing antibodies: a network meta-analysis across vaccines. Vaccines (Basel) 2021;9(3):227. DOI: 10.3390/vaccines9030227.

5. Farina $M$, Lavazza A. Advocating for greater inclusion of marginalized and forgotten populations in COVID19 vaccine rollouts. Int J Public Health 2021;66:1604036. DOI: 10.3389/ijph.2021.1604036. 